\title{
Development of the Gerbil Inner Ear Observed in the Hemicochlea
}

\author{
Claus-Peter Richter, Roxanne Edge, David Z. Z. He, and Peter Dallos
}

Auditory Physiology L aboratory (T heH ugh Knowles Center), Departments of N eurobiology and Physiology and Communication Sciences and Disorders, The Institute of N euroscience, Northwestern University, Evanston, IL 60208, USA

Received: 19 January 2000; Accepted: 26 June 2000; Online publication: 26 September 2000

\begin{abstract}
A frequency-dependent change in hearing sensitivity occurs during maturation in the basal gerbil cochlea. This change takes place during the first week after the onset of hearing. It has been argued that the mass of a given cochlear segment decreases during development and thus increases the best frequency. Changes in mass during cochlear maturation have been estimated previously by measuring the changes in cochlear dimensions. Fixed, dehydrated, embedded, or sputter-coated tissues were used in such work. However, dehydration of the tissue, a part of most histological techniques, results in severe distortion of some aspects of cochlear morphology. The present experiments, using a novel preparation, the hemicochlea, show that hydrated structures, such as the tectorial membrane and the basilar membrane hyaline matrix, are up to $100 \%$ larger than estimated previous studies. Therefore, the hemicochlea was used to study the development of cochlear morphology in the gerbil between the day of birth and postnatal day 19 . We used no protocols that would have resulted in severe distortion of cochlear elements. Consequently, a detailed study of cochlear morphology yields several measures that differ from previously published data. Our experiments confirm growth patterns of the cochlea that include a period of remarkably rapid change between postnatal day 6 and 8 . The accelerated growth starts in the middle of the cochlea and progresses toward the base and the apex. In particular, the increase in height of Deiters' cells dominated the change, "pushing" the tectorial
\end{abstract}

Correspondence to: Dr. Claus-Peter Richter - Northwestern University - Frances Searle Building - 2299 North Campus Drive - Evanston, IL 60208. Telephone: (847) 491-4648; fax: (847) 491-2523; email: cri529@nwu.edu membrane toward scala vestibuli. This resulted in a shape change of the tectorial membrane and the organ of Corti. The tectorial membrane was properly extended above the outer hair cells by postnatal day 12. This time coincides with the onset of hearing. The basilar membrane hyaline matrix increased in thickness, whereas the multilayered tympanic cover layer cells decreased to a single band of cells by postnatal day 19. Before and after the period of rapid growth, the observed gross morphological changes are rather small. It is unlikely that dimensional changes of cochlear structures between postnatal days 12 and 19 contribute significantly in the remapping of the frequency-place code in the base of the cochlea. Instead, structural changes affecting the stiffness of the cochlear partition might be responsible for the shift in best frequency.

Keywords: cochlea, development, hearing, anatomy, morphology, frequency-place code, hemicochlea

\section{INTRODUCTION}

It has been shown that the onset of hearing occurs in gerbils at about postnatal day 12. At this time, cochlear microphonics and compound action potentials can be recorded. However, after the onset of hearing, the cochlea still matures (Fink et al. 1972; Harris and Dallos 1984; Yancey and Dallos 1985; Woolf and Ryan 1984, 1988; Woolf et al. 1986; Arjmand et al. 1988; Echteler et al. 1989; Muller et al. 1991; He et al. 1994; McGuirt et al. 1995; Ito et al. 1995; M uller 1996; Souter et al. 1995, 1997; O verstreet and Ruggero, 1998, 1999; $\mathrm{He}$ and Dallos 1999; Richter and Dallos 2000). If electrical responses from a single location in the cochlea are monitored at successive times after the onset of 
hearing, a shift toward higher frequencies of about 1.5 octaves of the "best" stimulus frequency can be detected over several days, at least in the base of the cochlea (Harris and Dallos 1984; Yancey and Dallos 1985; Arjmand et al. 1988; Echteler et al. 1989; Muller et al. 1991; Muller 1996; O verstreet and Ruggero 1998, 1999; Richter and Dallos 2000).

Whether the remapping of the frequency-place code originates from the development of the cochlear amplifier (Norton et al. 1991; He et al. 1994; Mills et al. 1994; Mills and Rubel 1996, 1998) or is brought about by changes of passive cochlear mechanics (Overstreet and Ruggero 1998, 1999; Richter and Dallos 2000) has been examined. The results show that passive cochlear mechanics contribute significantly to the frequency-place code remapping. Passive cochlear mechanics are determined by the dimensions and physical properties ( mass and stiffness) of the selected cochlear segment. Developmental changes in mass can be estimated by measuring cochlear dimensions. $\mathrm{H}$ owever, in the majority of available work, cochlear anatomy has been studied in embedded and dehydrated material. It has been noted by several investigators that protocols used to embed or sputter-coat tissue for electron microscopy result in severe distortion of gellike structures (Kronester-Frei 1978, 1979; Lim 1972, 1977). M ore recently, Edge et al. (1998) reemphasized that distortion of the organ of Corti occurs as a result of dehydration protocols that are a part of the embedding procedures. In particular, gel-like structures such as the tectorial membrane or the basilar membrane matrix are severely affected. In other words, gradients in cochlear dimensions that occur during maturation of the inner ear might be masked by dehydration of cochlear structures.

With the hemicochlea (Edge et al. 1998), it is possible to visualize cochlear cross sections in a radial view without using dehydration protocols. The present experiments are designed to study changes in cochlear morphology between postnatal days, 0 and 19 (for review, see Rubsamen and Lippe 1997). Age-dependent growth of different cochlear elements, including the tectorial membrane, could be demonstrated in nondehydrated material. Measurements were performed at seven different locations in the cochlea. Results of the our experiments differ from the data of other groups, in particular for the aforementioned structures, which are likely to suffer severe distortion when dehydrated.

\section{METHODS}

Experimental procedures have been approved by the $\mathrm{NIH}$ and by the Northwestern U niversity Institutional Review Board.
Fixation of the cochlea

Mongolian gerbil (M erion es unguiculatus) pupsranging in age from 0 to 19 days after birth (DAB) were chosen for the experiments. The animals were given a lethal overdose of sodium pentobarbital (Nembutal) before cardiovascular perfusion was performed. First, the vascular system was flushed with a $\mathrm{H}$ anks Balanced Salt Solution which contained $20 \mu \mathrm{M}$ calcium $\left(\mathrm{HBSS}_{20}\right)$, about 1600 units of heparin (corresponding to $10 \mathrm{mg} /$ $100 \mathrm{ml}$; an anticoagulant) and $20 \mathrm{mg}$ methoxamine hydrochloride (a vasodilator).

Thereafter, the animals were perfused with $2.5 \%$ glutaraldehyde in a $\mathrm{HBSS}_{20}$ solution. $\mathrm{N}$ ext, the animals were decapitated and the bullae were removed. Finally, the cochleae were har vested. The stapes was dislodged and the round window membrane was punctured. Once more the cochleae were placed in a $2.5 \%$ glutaraldehyde fixative bath for approximately one hour. Then the specimens were rinsed three times in $\mathrm{HBSS}_{20}$ and excess bone was trimmed from the cochleae.

\section{Hemicochlea}

After appropriate fixation, as described above, the bony inner ears were fixed with acrylic (Locktite 404, $\mathrm{H}$ artford, CT) to a rectangular metal block placed in a TPI vibratome (TPI, St. Louis, MO). A small droplet of $\mathrm{HBSS}_{20}$ was placed on both the round window and stapes to bathe the cochlea and to prevent fluid evaporation while the glue was consolidating. Next, the specimen was immersed in $\mathrm{HBSS}_{20}$ and positioned in the cutting bath of the vibratome. A broken half of a double-edged razor blade was inserted into the blade holder and then brought forward slowly toward the cochlea. The height of the specimen was adjusted so that the blade was aligned with the midmodiolar plane. The blade was returned to its original position and the speed and amplitude were selected for cutting. The vibration amplitude of the blade was set to 200 $\mu \mathrm{m}$ and the advancement of the blade was $2 \mathrm{~mm} /$ min. Depending on the ease of the cut, the forward movement of the blade was reduced. Once the entire cochlea was cut, from apex to base, the speed and amplitude were returned to zero. The specimen was lowered to prevent damage to the cochlea when the blade returned to its original position. The cochlear halves (hemicochleae) were carefully removed from the rectangular block and were transferred into a petri dish lid for proper orientation. Alignment of the hemicochlea was accomplished by placing it on a small bed of high vacuum grease (Dow Corning, Corporation Midland, MI, USA), which was immersed in $\mathrm{HBSS}_{20}$. Finally, the petri dish was placed on the stage of an upright microscope. 


\section{Experimental setup}

The experimental setup consisted of an upright Leitz microscope (Medilux Stuttgart, Germany), which was equipped with $10 \times, 20 \times$, magnification and $40 \times$ Olympuswater immersion lenses, an optivar $(1 \times-2 \times)$, and a trinoc viewing head. Pictures of the hemicochlea preparation were taken with a CCD camera [Panasonic GP-MF602 (Secaucus, NJ, USA) or O ptronics DEI 450 (Goleta, CA, USA)], which was attached to one port of the viewing head. Despite most of the organ of Corti tissues being light transparent, different translucent structures could still be visualized by oblique illumination. In the present experiments the light source was a series of five bright light-emitting diodes (LEDs) arranged below the microscope's condenser. The position of the LEDs was off the optical axis so that the preparation could be illuminated by oblique light. $A$ video enhancement system (Argus 20, Hamamatsu, Bridgewater, NJ, USA) was utilized to improve the contrast of the images, which then were stored on both an optical laser disk recorder (Panasonic) and in the computer. The video enhancement system was also used to acquire the desired cochlear dimensions from the captured images.

\section{Calibration}

Measurements of the cochlear structures were made using the software package $\mathrm{NIH}$-image. The system was calibrated for each magnification by using the video image of a calibration slide that was captured at the end of each series of image acquisition. Thus, it was possible to convert the number of image pixels into for linear dimension or for cross-sectional areas.

\section{Length and width measurements}

Various dimensions of cochlear structures were evaluated as shown in Figure $1 \mathrm{a}, \mathrm{b}$. Included are the radial length of the tectorial membrane (TM), the widths of the pectinate and arcuate zones of the basilar membrane (BM), the height of the inner and outer pillar cells, the height of the inner and outer hair cells, the height of Deiters' cells, the height of the spiral limbus, the thickness of the layer of Claudius cells, the thickness of the matrix of the zona pectinata of the BM, and the concatenated height of the Claudius cells $(C L)$ plus BM hyaline matrix (HM) plus tympanic cover layer cells (TCL). Other measures obtained were the thickness of the TCL of the pectinate zone of the BM and the thickness of the TM measured directly atop Hensen's stripe (HS).

\section{Angles}

As shown in Figure 1c, angles between selected structures were also determined: the angle between the outer pillar stalk and the reticular lamina above the three rows of outer hair cells $(\alpha)$, the angle between the basal lamina of the arcuate zone and the outer pillar stalk $(\beta)$, and the angle between the inner pillar stalk and the basal lamina of the arcuate zone $(\gamma)$.

\section{Cross-sectional surface areas}

Area measurements were obtained bytracing the structures of interest. The total number of pixels within the circumscribed area were counted and gave a measure of the cross-sectional area. As shown in Figure $1 d$, for all age groups, the surface area of the organ of Corti (area B) is defined by the boundaries at the reticular lamina, Hensen's cells, the basal lamina of the basilar membrane, and upward along the inner phalangeal supporting cell. Area measurements of the tectorial membrane and its marginal band (area A), the inner spiral sulcus (area D), as well as the matrix found in the zona pectinata of the basilar membrane (area C) are as indicated.

\section{Basilar membrane length measurements}

The total length of the basilar membrane was determined using two methods. One length measurement was achieved by reconstructing the cochlear duct from several cochlear segments resulting from the cutting procedure. The latter was accomplished by lightly osmicating, dehydrating, infiltrating, and embedding the two corresponding hemicochleae in plastic (Araldite-Epon Polyscience Inc., Warrington, PA, USA). $\mathrm{H}$ alf-turn cochlear segments were then extracted from the embedded hemicochlea. Care was taken to shave away the bone above and below the embedded organ. Thus, the pillar heads were clearly seen when viewing the tissue on an upright microscope at a low magnification. A video camera was attached to the microscope and the image of the cochlear segment was displayed on a video monitor. Next, an acetate sheet was taped to the calibrated video display. An arc was traced longitudinally between the pillar heads and then measured as described by Bohne (1972). All half-turn segments were totaled to obtain a final length measurement of the basilar membrane. To assure that cutting of the cochlea does not result in shorter lengths of the basilar membrane due to lost pieces during the procedures, intact cochleae were reconstructed as well.

Because we are aware that procedures that include dehydration and embedding might severely distort the cochlear preparation, we also obtained length measurementsfrom only fixed preparations ( without dehydration). With our second approach the bony shell of the cochlea was removed after fixation. Thereafter, stria vascularis was removed carefully and each turn of the cochlea was har vested individually. Cochlear 


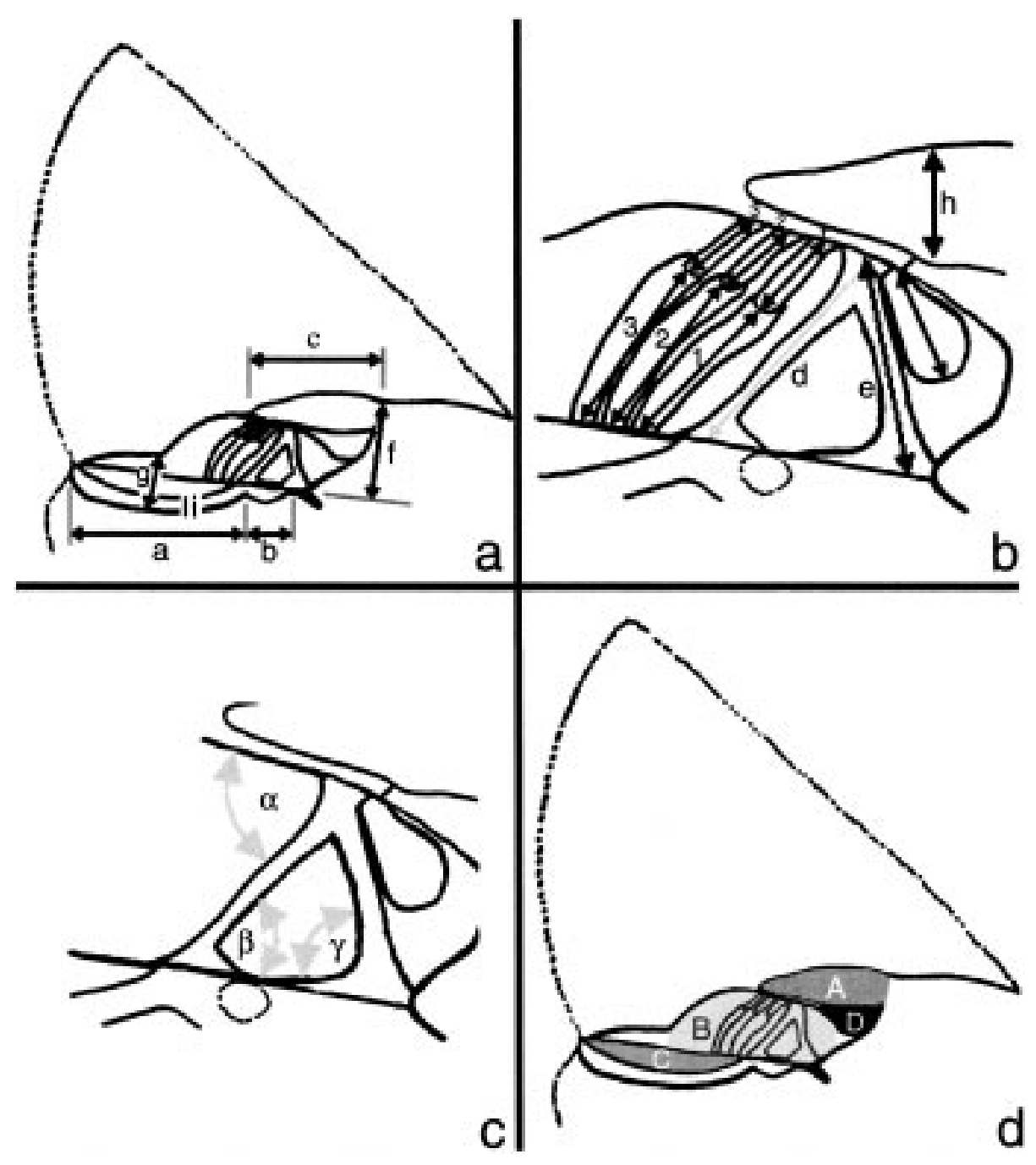

FIG. 1. Sketch of the radial view of one turn of a hemicochlea. Linear measures were taken as shown in a and b. Measures are the width of the basilar membrane pectinate zone (a) and arcuate zone $(b)$ and tectorial membranes (c), the height of the inner and outer pillar cells $(e$ and $d)$, the height of the inner sulcus $(f)$, the summed height of the basilar membrane and the Claudius cells $(g)$, the height of the tectorial membrane $(h)$, and the thickness of the tympanic cover layer cells (i). Height of the outer hair cells and the bodies of Deiters' cells are measured as shown by the arrows in b. (c) Different angles are measured: the angle between the outer pillar stalk and the reticular lamina $(\alpha)$, the angle between a line parallel to the BM and a line through the outer pillar stalk $(\beta)$, and the angle between a line through the inner pillar stalk and the basal lamina $(\psi)$. (d) Crosssectional area measurements were obtained according to the shaded areas for the tectorial membrane (A), organ of Corti (B), the hyaline matrix of the basilar membrane $(\mathrm{C})$, and the inner spiral sulcus (D). segments were placed under an upright microscope and the images that were captured with a CCD camera were displayed on the screen of a monitor. The segments were traced along the pillar heads and added piece-by-piece to yield the total length of the basilar membrane.

\section{Controls}

Distortion of the organ of Corti might result from the fixation. To control for such distortions, cross sections were observed before, during, and after perfusion with the fixative used in the experiments. A hemicochlea was cut and thereafter an image of the radial cross section of the organ of Corti was taken as soon as possible. The time between sacrificing the animal (no intracardiac perfusion) and capturing the first image was less than 20 minutes. After a control image was taken, the $\mathrm{HBSS}_{20}$ bath solution was exchanged for a $2.5 \%$ glutaraldehyde-containing $\mathrm{HBSS}_{20}$ solution. While the fixative was perfused into the dish containing the cochlea, successive images of the organ of
Corti were taken. Effects of the fixative were determined by comparing the captured images before and after perfusion.

\section{Statistics}

Averages and standard deviations, as well as medians and interquartile ranges were calculated for the measurements obtained for various cochlear dimensions as outlined in Figure 1. The values shown in the subsequent figures are the medians and their respective interquartile ranges. For some measures a paired t-test with a criterion value of $p<0.05$ was performed to determine whether the difference between the means of the measures is significant.

\section{RESULTS}

The development of different structures in the gerbil inner ear was examined between postnatal days 0 and 


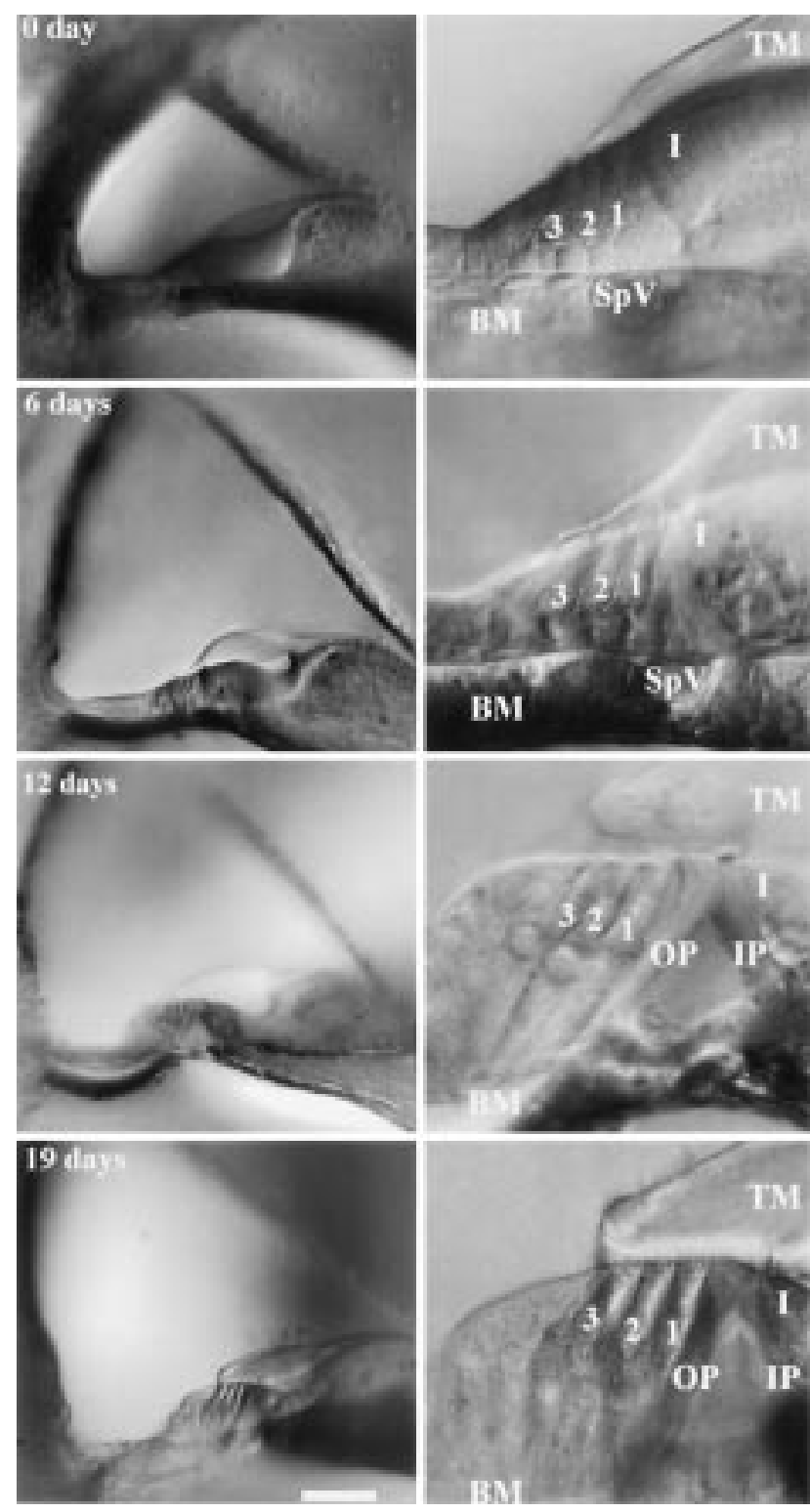

FIG. 2. Images of the cochlea in different stages of development, taken in the basal turn of the hemicochlea. The ages chosen were 0 day, 6 days, 12 days, and 19 days. The scale bar equals $100 \mu \mathrm{m}$ for the left column and $25 \mu \mathrm{m}$ for the right column. The labeled structures are the tectorial membrane (TM), the inner hair cell (I), the inner pillar and outer pillar cell (IP, OP), three rows of outer hair cells (1, $2,3)$, the spiral vessel $(\mathrm{SpV})$, and the basilar membrane (BM). The tissue was fixed prior capturing the images.

19. In total 72 animals were used in the study: 8 at $D A B \quad 0,4$ at $D A B 3,7$ at DAB 6, 2 at DAB 7, 5 at $D A B$ 8,2 at DAB 9, 2 at DAB 10,12 at DAB 12, 7 at DAB 13,6 at $D A B 15$, and 13 at $D A B 19$.

In contrast to studies conducted by other groups, in our experiments no dehydration protocols were used. It has recently been reemphasized that dehydration of the cochlea generates severe distortion of the inner ear structures (Edge et al. 1998). In Figure 2 the typical cross-sectional views of the hemicochlea preparation are shown at postnatal days $0,6,12$, and 19. Both low- and high-magnification images are provided.

\section{Controls}

Cutting of the cochlea along its modiolar axis often results in partial damage of the preparation. The most common distortions resulting from cutting are the detachment of the tectorial membrane, the stria vascularis, or the spiral ligament. Significant distortions can be detected easily by inspection. H owever, one cannot rule out some microscopic loosening of the tectorial membrane from the outer hair cells. Perfect condition of the cross-sectional area of a half-turn is judged by the following criteria: straight inner and outer pillar cells, cylindrical outer hair cells of uniform diameter, no bending between basilar membrane arcuate and basilar membrane pectinate zones, and tectorial membrane closely apposed to the third row of outer hair cells. The most sensitive measure for the condition of the preparation was the position of the inner hair cell stereocilia bundles. When the cochlea preparation deteriorated, the first visible sign was a separation of inner hair cell stereocilia from Hensen's stripe.

In the present experiments several locations from the base to the apex of the cochlea were examined in any one preparation. Acquisition of video images for any given location of one hemicochlea requires approximately 2.5 hours. Unfortunately, after cutting the hemicochlea, the cochlear structures quickly deteriorate so that only a few images could be captured with the preparation in good condition. In particular, outer hair cells and Deiters' cells changed their shape rapidly. Within 30 minutes outer hair cells decreased their length about $25 \%$. To prevent these changes, the cochleae were fixed by a rapid intracardiac perfusion. Thereafter, the cochlea preparation remained in stable condition. To determine whether the fixative, by itself, generates distortion of the cochlear structures, the half-turns were superfused with $2.5 \%$ glutaraldehyde immersed in $\mathrm{HBSS}_{20}$. Images of the cross sections, taken before and after perfusion, did not differ significantly (Fig. 3). The changes for the different structures were less than $2 \%$, except the hyaline matrix and the tectorial membrane (Fig. 3). As previously reported, due to fixation with $2.5 \%$ glutaraldehyde, the crosssectional area of the tectorial membrane shrunk about $5 \%$ and the cross-sectional area of the basilar membrane hyaline matrix decreased about 4\% (Edge et al. 1998). The changes observed were not significant $(N=6)$. This justified the use of fixatives to stabilize the preparation.

Repeatability of the measurements was tested for one examiner who remeasured the height of the pillar 

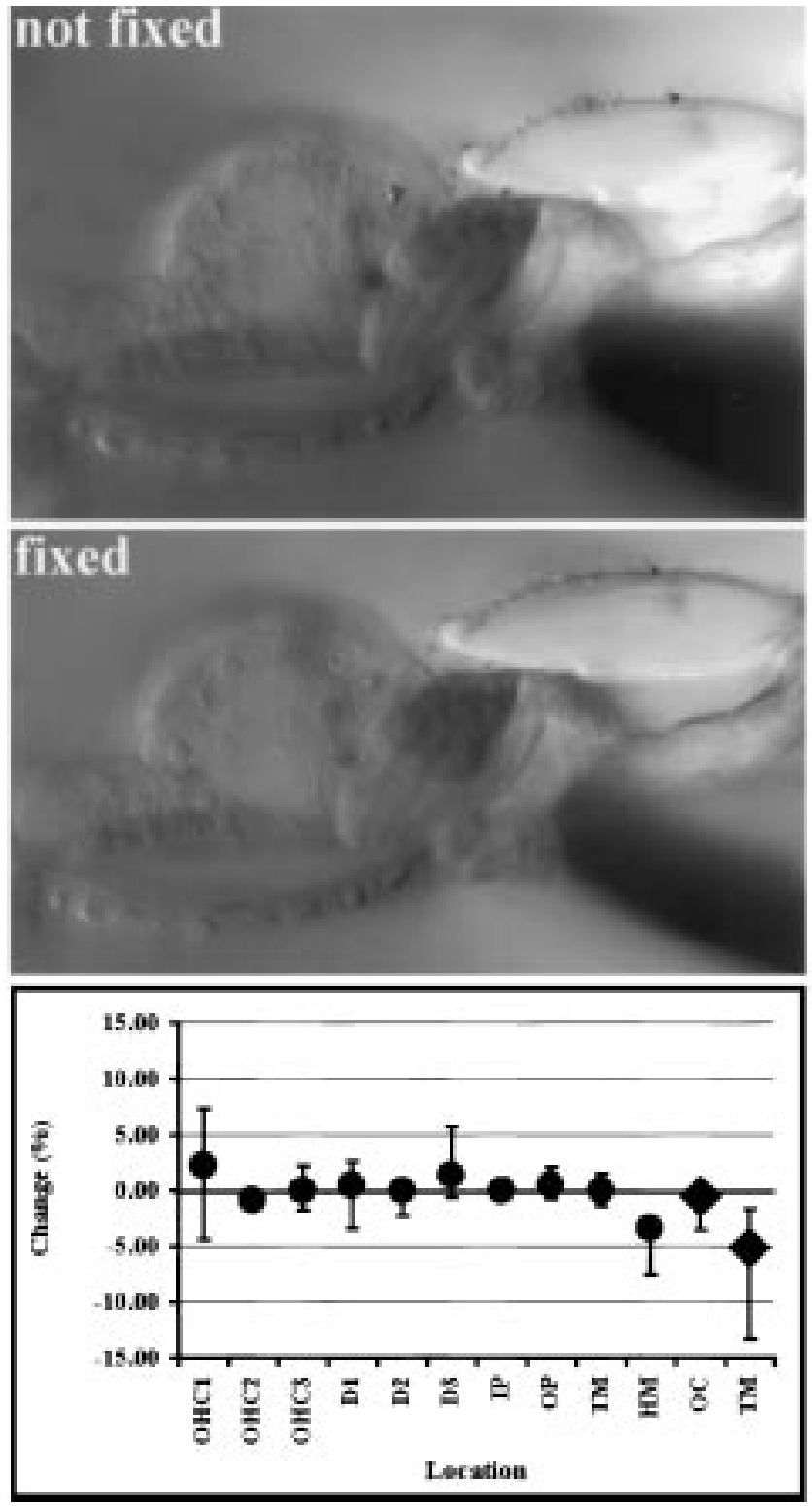

FIG. 3. Control experiments comparing fixed and unfixed tissue. Shown are parts of the organ of Corti under high magnification. The circles in the graph show the differences in height before and after fixation of outer hair cells (OHC1, OHC2, OHC3), Deiters' cells (D1, D2, D3), inner and outer pillar cells (IP, OP), hyaline matrix (HM), and the tectorial membrane (TM). The diamonds show changes in area measurements of the organ of Corti (OC) and the tectorial membrane (TM). None of the changes are significant. The values are the medians and their respective interquartile ranges.

cells, the height of outer hair cells, and the crosssectional area of the tectorial membrane in the same preparation more than four weeks apart. The variations between the measurements were less than $\pm 5 \%$. Similarly, the results of the measurements obtained by three different examiners were compared. Again, the differences among the measures obtained by the different individuals did not differ by more than $\pm 5 \%$.

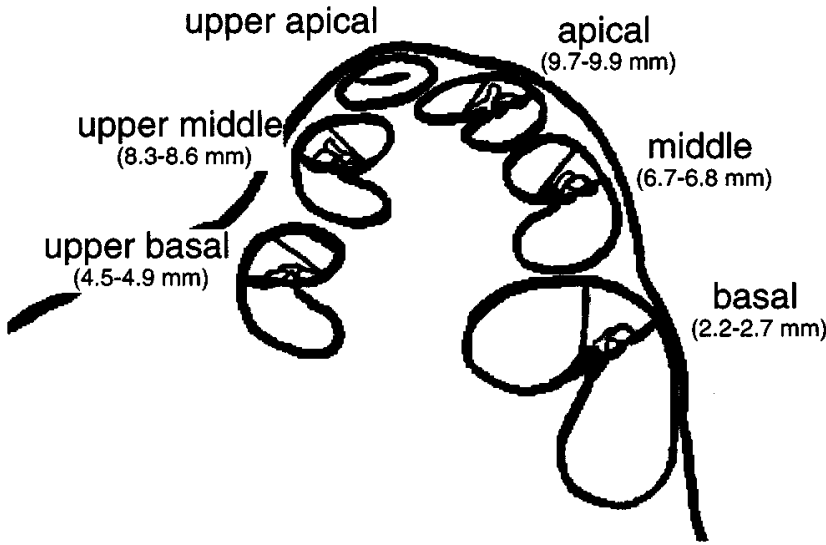

FIG. 4. Radial view of a hemicochlea. Nomenclature and distances of the cut edges from the basal end of the basilar membrane are shown for the different turns.

\section{Locations of measurements}

Alter cutting the cochlea, seven different cut locations could be distinguished. The cut edges are designated as the hook, the basal turn, the upper basal turn, the middle turn, the upper middle turn, the apical turn, and the upper apical turn. Figure 4 shows these landmarks and the approximate distances (in millimeters) for these cut edges from the basal end of the basilar membrane. The success rate for the number of measuring sites available in a preparation depended on the age of the animal. Whereas in young gerbils most preparations revealed pristine conditions for all seven locations, in adult animals the number of sites in good conditions usually decreased to four.

\section{Basilar membrane (BM)}

For an adult animal the length of the basilar membrane in dehydrated and embedded tissue was 11.1 $\mathrm{mm}(\mathrm{N}=3)$ and in fixed (but not dehydrated) material it was $11.4 \mathrm{~mm}(\mathrm{~N}=3)$.

At day zero the width of the basilar membrane in the base of the cochlea was $146 \mu \mathrm{m}$ ( $25 \mu \mathrm{m}$ the arcuate zone and $121 \mu \mathrm{m}$ the pectinate zone). Longitudinal gradients in the width of the basilar membrane were not found at this age; however, the hook region was narrower than the rest of the basilar membrane (Fig. 5). During development the width of the basilar membrane increased, particularly at the middle and apical locations of the cochlea. Nineteen days after birth the

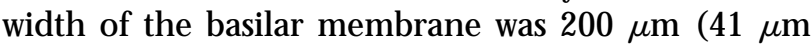
the arcuate zone and $159 \mu \mathrm{m}$ the pectinate zone) at the basal end of the cochlea (not the hook), $264 \mu \mathrm{m}$ (54 $\mu \mathrm{m}$ the arcuate zone and $210 \mu \mathrm{m}$ the pectinate zone) at the upper middle turns, and $252 \mu \mathrm{m}$ ( $61 \mu \mathrm{m}$ the arcuate zone and $191 \mu \mathrm{m}$ the pectinate zone) in the apex of the cochlea (Fig. 5). 


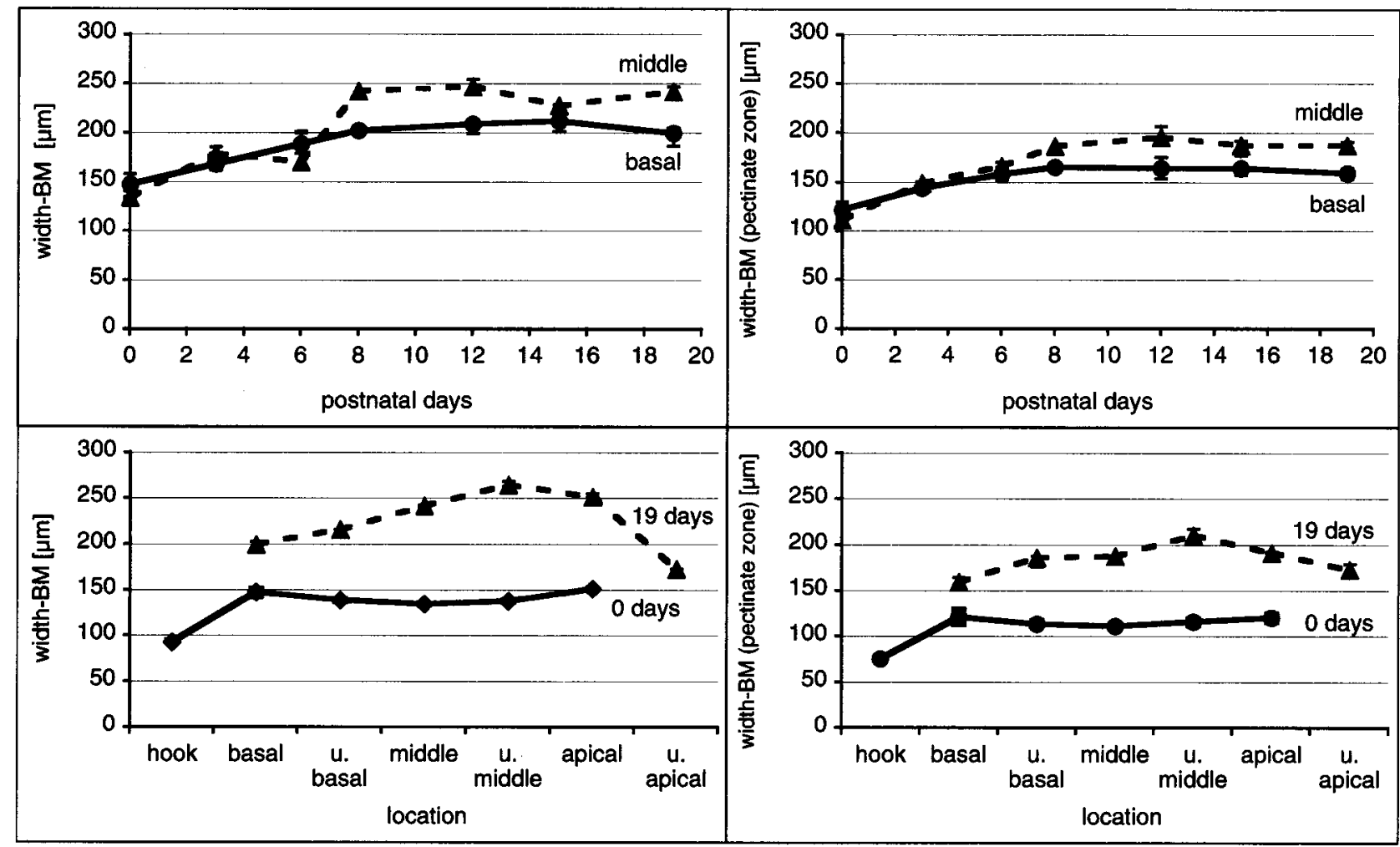

FIG. 5. Width of the basilar membrane (upper left panel) and the basilar membrane pectinate zone (upper right panel). An increase in width of both basilar membrane and basilar membrane pectinate zone can be seen with age. Lower panels show the developmental gradients along the cochlea for basilar membrane and basilar membrane pectinate zone. The values are the medians and their respective interquartile ranges.

During hemicochlea preparation, the tympanic cover layer cells $(T C L)$, the hyaline matrix of the basilar membrane (HM), and the Claudius cells $(\mathrm{CL})$ could be noted. The concatenated thickness of the $T C L$, the $H M$, and the $C L$ at postnatal day 0 was about $60 \mu \mathrm{m}$. No longitudinal gradients could be seen. During development the thickness of tympanic cover layer cells decreased, whereas the hyaline mass developed between the upper and the lower fiber bands of the basilar membrane. In the basal, upper basal, and middle turns the concatenated thickness of $T C L, H M$, and $\mathrm{CL}$ first increased until about postnatal day 12 . Thereafter, the summed thickness of $\mathrm{BM}$ and $\mathrm{CL}$ decreased again (Fig. 6). In the basal turn, similar values are reached in adult animals as measured in a newborn animal, whereas in the middle and uppermiddle turn the thickness clearly increased above the dimensions obtained at birth. Interestingly, between postnatal day 12 and adulthood, the total thickness of $T C L, H M$, and $C L$ decreased, whereas for more apical locations it still increased. At postnatal day 19, the thickest site along the cochlea was about $8.5 \mathrm{~mm}$ from the basal end of the basilar membrane (Fig. 6). In general, changes in the above-discussed dimensions are not dramatic, either with development or along the length of the cochlea.
As seen in Figure 7, the cross-sectional area of the basilar membrane (hyaline) matrix changed dramatically between postnatal days 6 and 8 . In the base of the cochlea, the cross-sectional area grew from almost nothing to $2100 \mu \mathrm{m}^{2}$. Longitudinal gradients developed as well. The cross-sectional area of the basilar membrane hyaline matrix increased from $2200 \mu \mathrm{m}^{2}$ (in the base) to $4995 \mu \mathrm{m}^{2}$ (at about $8.5 \mathrm{~mm}$ from the basal end of the BM). Further toward the apex of the cochlea, the cross-sectional area of the $\mathrm{H} M$ decreased to $4290 \mu \mathrm{m}^{2}$ and about $3000 \mu \mathrm{m}^{2}$ in the helicotrema region.

Tectorial membrane (TM)

Already at birth, two segments of the tectorial membrane can be distinguished: a more structured body and a segment extending from the body across the outer hair cells and seemingly attaching to H ensen's cells. After birth, changes in the cross-sectional area of the TM are small in the base of the cochlea compared with the changes that can be observed at more apical locations (Fig. 8). In addition to an increase in the cross-sectional area, dramatic shape changesoccur between postnatal days 6 and 12, during the rapid increase in height of Deiters' cells and the outer hair 


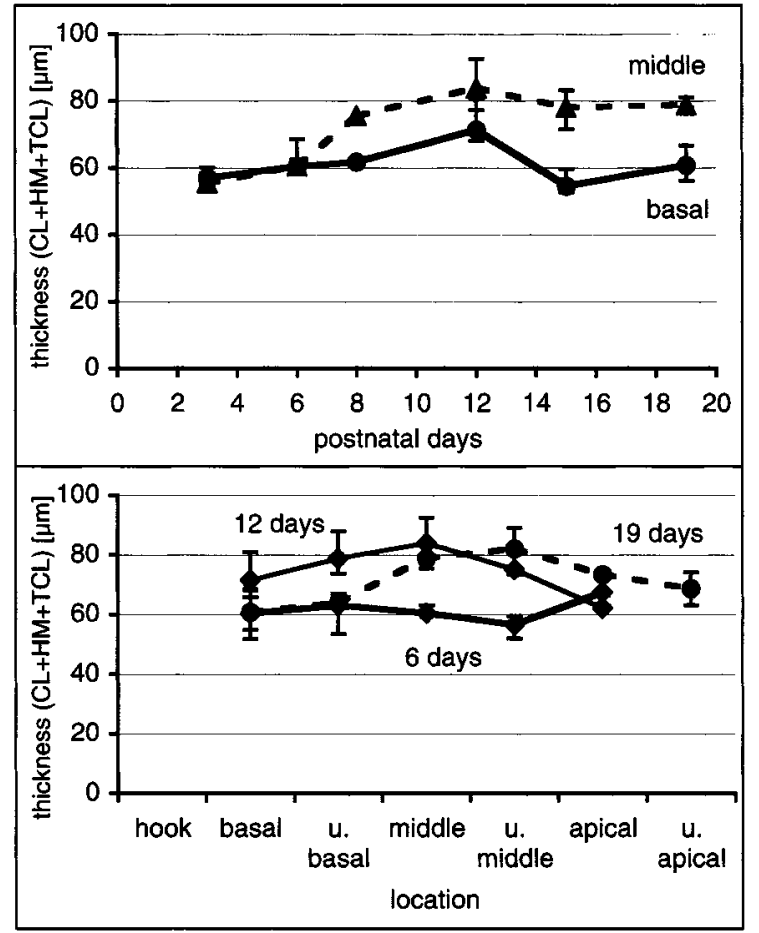

FIG. 6. Thickness of the basilar membrane (sum of tympanic cover layer cells and hyaline matrix) and the Claudius cells. The summed thickness of the basilar membrane and Claudius cells increases during development for more apical turns, whereas it decreases in the base after postnatal day 12. However, compared with birth, even in the base the total thickness of basilar membrane and Claudius cells did not change significantly. Most rapid changes are between postnatal days 6 and 8 . The values are the medians and their respective interquartile ranges.

cells (Fig. 9). Thickness and width of the body of the tectorial membrane changed the most between postnatal days 0 and 6 . Likewise, the cross-sectional area of the body of the tectorial membrane varied the most between postnatal days 0 and 6 , particularly in the more apical turns (Fig. 10) .

\section{Organ of corti and its cellular structures}

The organ of Corti drastically changes its cross-sectional area during maturation. At birth, the cross-sectional area increases monotonically from the base of the cochlea $\left(2150 \mu \mathrm{m}^{2}\right)$ toward the apex $\left(2580 \mu \mathrm{m}^{2}\right)$. Induced by the increase in the height of Deiters' cells, the fastest growth occurs between postnatal days 6 and 8 (Fig. 11). Deiters' cells located in the basal turn are about $10 \mu \mathrm{m}$ long at birth. Their height remainsalmost unchanged until postnatal day 6 . Thereafter, within two days, their height increases to $50 \mu \mathrm{m}$ (Fig. 11). The first changes could be observed at the upper basal turn (about $4.8 \mathrm{~mm}$ from the basal end of the basilar membrane, Fig. 12). Later growth occurs in the more basal and apical locations. In order to produce a better
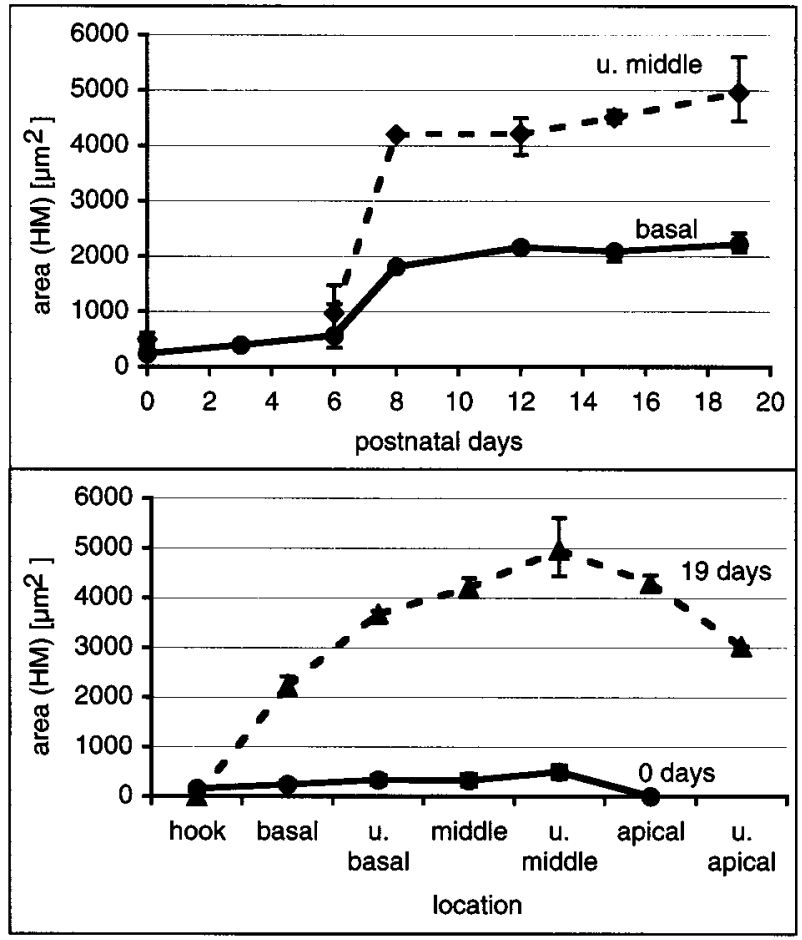

FIG. 7. The growth of the area of the hyaline matrix. Longitudinal gradients are observable in adult animals (lower panel). The maximum is seen at about $8.3-8.6 \mathrm{~mm}$ from the basal end. The period of rapid growth is between postnatal days 6 and 8 (upper panel). The values are the medians and their respective interquartile ranges.

understanding of the rapid-growth period, the time pattern of the onset of rapid growth was reexamined in a series of animals that were taken from one single litter. The animals were sacrificed during the time period of rapid growth, two animals precisely every 24 hours over a time span of three to four days. The resulting data are shown in Figure 12.

At birth, inner and outer pillar cells are approximately the same height throughout the cochlea (Fig. 13). No longitudinal gradients are seen. Accelerated growth of the pillar cells can be detected between postnatal days 6 and 8 (Fig. 13). During this period outer pillar cells grow longer than the inner pillar cells (Fig. 13). Moreover, in adult animals a gradient in the height of both types of pillar cells can be seen along the cochlea.

O uter hair cells reveal similar growth patterns as Deiters' cells. At birth, little longitudinal difference can be observed in cell height (Fig. 14). The cells are about 20-25 $\mu \mathrm{m}$ long throughout the cochlea. A period of rapid growth is seen between postnatal days 6 and 8. Finally, at postnatal day 8, outer hair cells have almost reached their adult height. O uter hair cell height increases from about $20 \mu \mathrm{m}$ in the base to about $50 \mu \mathrm{m}$ in the apex. No significant differences in height of the outer hair cells of row $1(\mathrm{OHCl})$ 


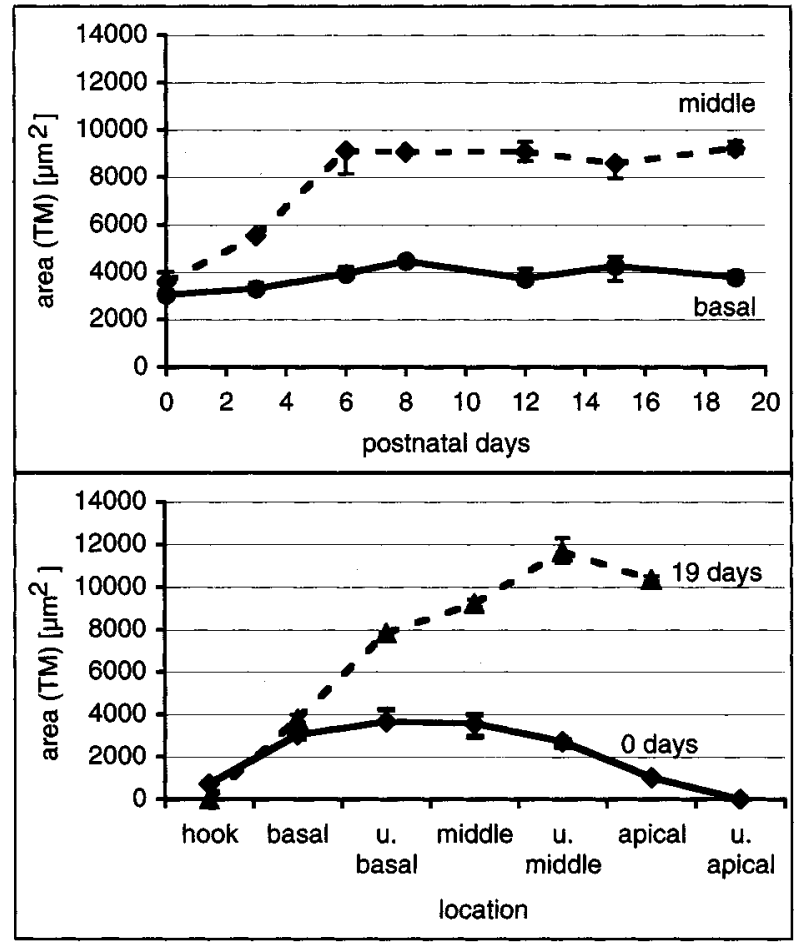

FIG. 8. Cross-sectional area of the tectorial membrane. Longitudinal gradients are shown in the lower panel. The largest cross-sectional area is found $8.3-8.6 \mathrm{~mm}$ from the basal end of the basilar membrane. (Upper panel) A rapid growth of the cross-sectional area occurs between birth and postnatal day 6 . Thereafter, only small changes in the cross-sectional area are detected. The values are the medians and their respective interquartile ranges.

versus outer hair cells of row $2(\mathrm{OHC} 2)$ or outer hair cells of row 3 ( $\mathrm{OHC} 3$ ) could be detected.

\section{Angles}

At birth the outer pillar cell forms roughly a right angle $(\beta)$ with the basilar membrane and an angle of about $75^{\circ}$ with the reticular lamina $(\alpha)$, whereas the inner pillar cell reveals an angle of about $65^{\circ}(\gamma)$. When the cochlear duct opens between postnatal days 2 and 3 , the outer pillar cell initially remains perpendicular to the basilar membrane, whereas the inner pillar cells reveal an angle of about $55^{\circ}$. During development, the feet of the pillar cells separate. In addition to the inner and outer pillar feet separating ( widening of the arcuate zone; see Fig. 5), the pillar cells grow in height; the outer pillar cell more than the inner pillar cell. The result is a decrease in the angle between the stalk of the outer pillar cell and the basilar membrane from about $90^{\circ}$ to $45^{\circ}$ (Fig. 15). Furthermore, the angle of the inner pillar cell stalk to the basilar membrane increases from about $55^{\circ}$ to $70^{\circ}$ (Fig. 15). Interestingly, there is little variation in the latter angles throughout the cochlea.

The angle between the outer pillar cell stalk and

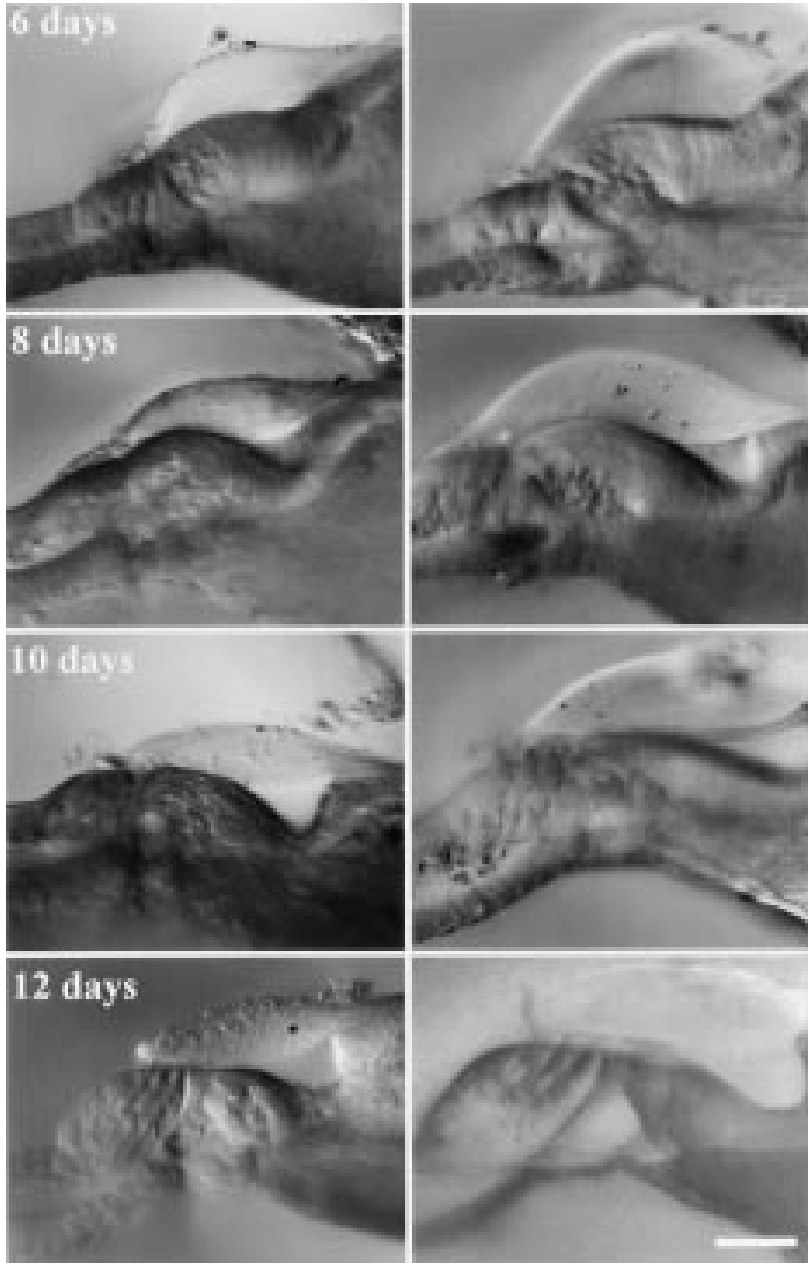

FIG. 9. Sequence of images taken in basal turns (left column) and middle turns (right column) at postnatal days $6,8,10$, and 12 . The rapid growth of Deiters' cells and outer hair cells "pushes" the tectorial membrane toward the scala vestibuli. The inner spiral sulcus already started to open. Finally, at postnatal day 12, outer hair cells were located below the structured segment of the tectorial membrane. This time coincides with the reported onset of hearing. Scale bar equals $50 \mu \mathrm{m}$.

the reticular lamina $(\alpha)$ decreases from $75^{\circ}$ to $67^{\circ}$. Little variation in this angle is seen along the cochlea.

\section{DISCUSSION}

Gerbils do not hear at birth. As shown by several groups, significant structural and functional changes occur in the cochlea and hearing develops over an approximately three-week period before it becomes adult like at about postnatal day 19 (Fink et al. 1972; Harris and Dallos 1984; Woolf and Ryan 1984, 1988; Yancey and Dallos 1985; Woolf et al. 1986; Arjmand et al. 1988; Echteler et al. 1989; $\mathrm{H}$ arris et al. 1990; Norton et al. 1991; He et al. 1994; Mills et al. 1994; Ito et al. 1995; M cGuirt et al. 1995; Muller et al. 1991; 

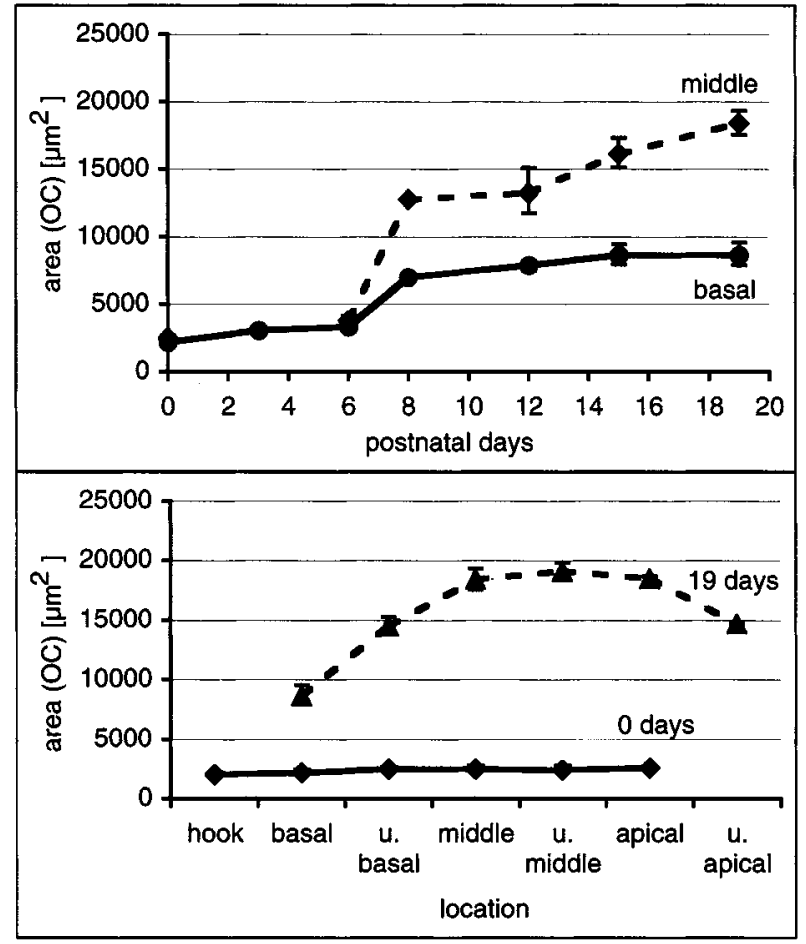

FIG. 10. The growth of the cross-sectional area of the organ of Corti. (Upper panel) It is apparent that the period of rapid growth occurs between postnatal days 6 and 8. (Lower panel) It is apparent that the biggest cross-sectional area is found in adulthood at about $8.4 \mathrm{~mm}$ from the basal end of the basilar membrane. No longitudinal gradients are found at birth. The values are the medians and their respective interquartile ranges.

Muller 1996; Mills and Rubel 1996, 1998; O verstreet and Ruggero 1998, 1999; Richter and Dallos 2000). Thereafter, only subtle maturation of cochlear function can be detected (McGuirt et al. 1995). Some morphological studies in the gerbil have addressed the maturation of gross morphology of the inner ear during this time period (Schweitzer et al. 1996; Souter et al. 1997). In these studies development of inner-ear structures was correlated with the physiology of hearing. It has been shown that during the first two weeks the basilar membrane (Souter et al. 1997), the inner and outer pillar cells, and the reticular lamina underwent significant changes in dimension (Souter et al. 1997). H owever, all previous studies used either fixed, dehydrated, or sputter-coated material. H ydrous structures, such as the tectorial membrane or the hyaline matrix of the basilar membrane, are subject to severe shrinkage from the dehydration (Lim 1972; Kronester-Frei 1978, 1979; Edge et al. 1998).

Because the mechanical properties (mass and stiffness) of the inner ear are notably determined by the dimensions and properties of the different structures, it is of special interest to obtain the undistorted dimensions of the inner ear. The hemicochlea allows us to study such dimensions, inasmuch as it is minimally

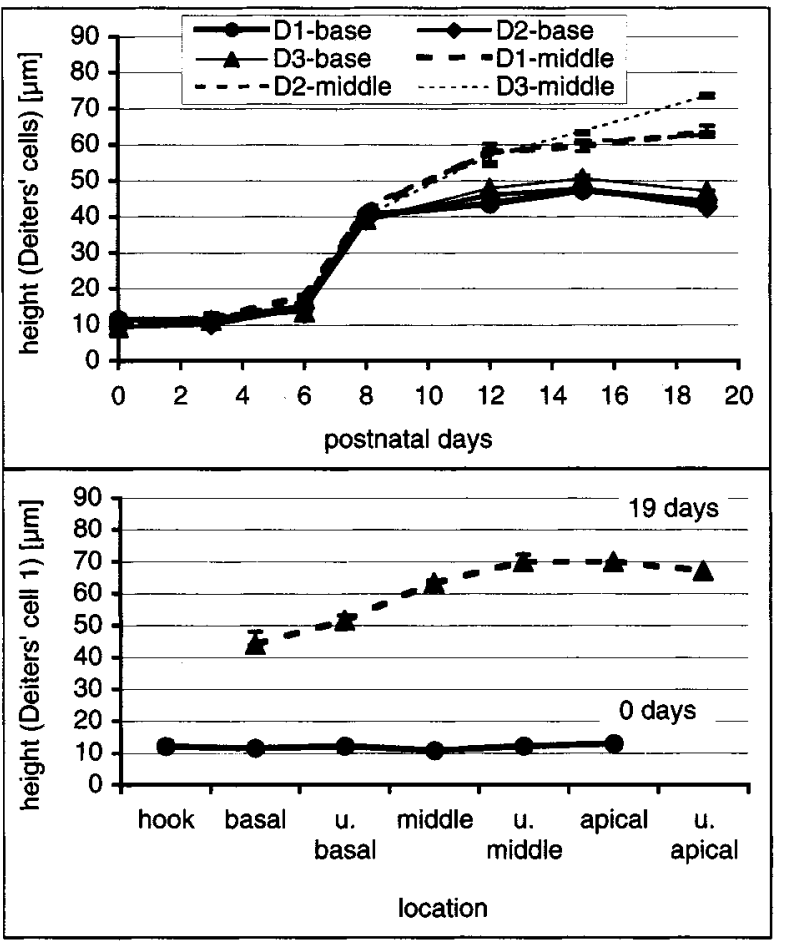

FIG. 11. The time pattern of the growth of the three rows of Deiters' cells. In immature cochleae, Deiters' cells have the same height along the cochlea (lower panel). After the period of rapid growth between DAB 6 and DAB 8, longitudinal height differences can bee seen. Cells are longer in the middle and apical locations along the cochlea. The period of rapid growth occurs between postnatal days 6 and 8 . It is not detectable from the upper panel whether maturation occurs in a base-to-apex time pattern. The values are the medians and their respective interquartile ranges.

affected by fixation (see below) or by the cutting procedures (Edge et al. 1998). O ur experiments present an itemized study of the development of the inner ear from birth of the animal to postnatal day 19. Developmental changes of the inner-ear dimensions and adult like morphology are presented in detail, in particular for hydrous structures of the inner ear.

Dimensional changes and frequency-place code remapping

A developmental shift of the frequency-place code of the basilar membrane was first suggested by Rubel and Ryals (1983). Their proposal was based on data from sound exposed chick cochleae. In gerbils, the characteristic frequency of single auditory nerve fibers that originate in the base of the cochlea shifts about 1.5 octaves toward higher frequencies (Echteler et al. 1989). Considering that the maturation of the cochlear amplifier might contribute a change in best frequency of about 0.6 octave, the remaining shift of approximately 1 octave needs to be explained. For simplicity, we consider a simple mass-spring resonant system for which the resonance frequency $\omega$ is calculated by 


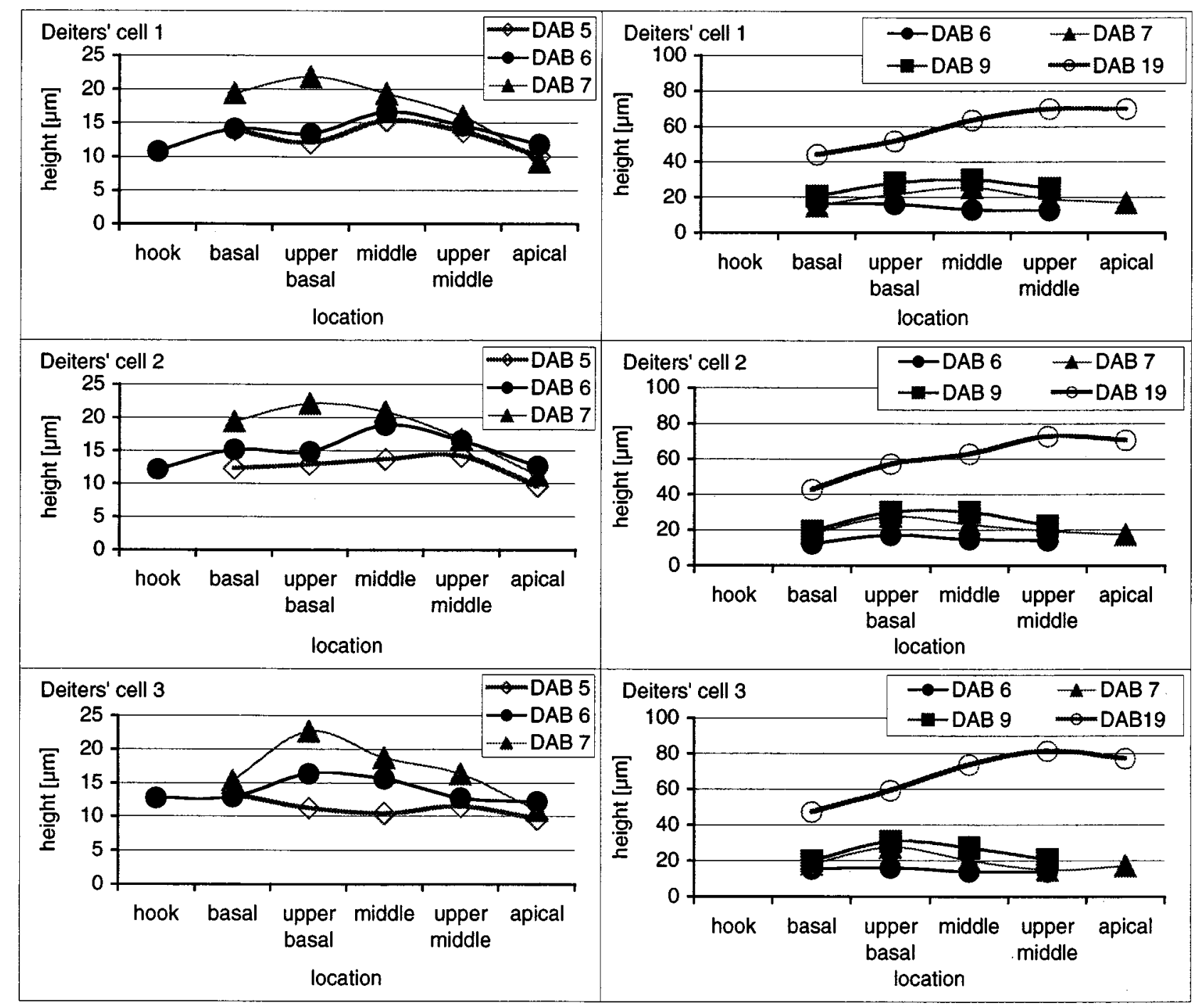

FIG. 12. Two examples used to determine time patterns in onset of rapid cochlear maturation. The height of Deiters' cells was measured at postnatal days 5, 6, 7, 8, and 9 in littermates. The animals were killed exactly 24 hours apart. The period of rapid growth is detectable in the upper basal turn first and then spreads toward the apex and the base.

$$
\omega=\sqrt{\mathrm{k} / \mathrm{m}}
$$

where $k$ is stiffness and $m$ is mass. Either stiffness has to increase by a factor of 4 or the mass has to decrease by a factor of 4 to result in a 1 octave shift of the resonant frequency. As a first approximation, similar numbers might be expected for the developmental change in cochlear-cross section to account for the residual 1-octave shift in best frequency. In the present study, changes are not seen for any of the basal cochlear dimensions between postnatal days 12 and 15 that would exceed a factor of 1.2. In particular, the areas of the basilar membrane, the organ of Corti, and the tectorial membrane were inspected. Dimensional changes were also minor for the concatenated thickness of the basilar membrane. In other words, mass changes due to change in gross cochlear morphology have seemingly minor contributions to the frequencyplace code shift in the base of the cochlea during development. Rather, change in stiffness (Echteler 1995) and/ or cochlear micromechanics (Richter and Dallos 2000) might be the major factor in the frequency-place code remapping between postnatal days 12 and 19.

Moreover, none of the previous studies that addressed this matter (Schweitzer et al. 1996; Souter et al. 1997) revealed a decrease of mass by a factor of 4. Mass has been represented by the cross-sectional area of the organ of Corti or the basilar membrane, respectively. In the base of the cochlea, Schweitzer et al. (1996) reported dimensional changes that were generally less than a factor of 1.2, except the area of the organ of Corti that decreased by a factor of 1.9. The dimensional changes in basilar membrane were 


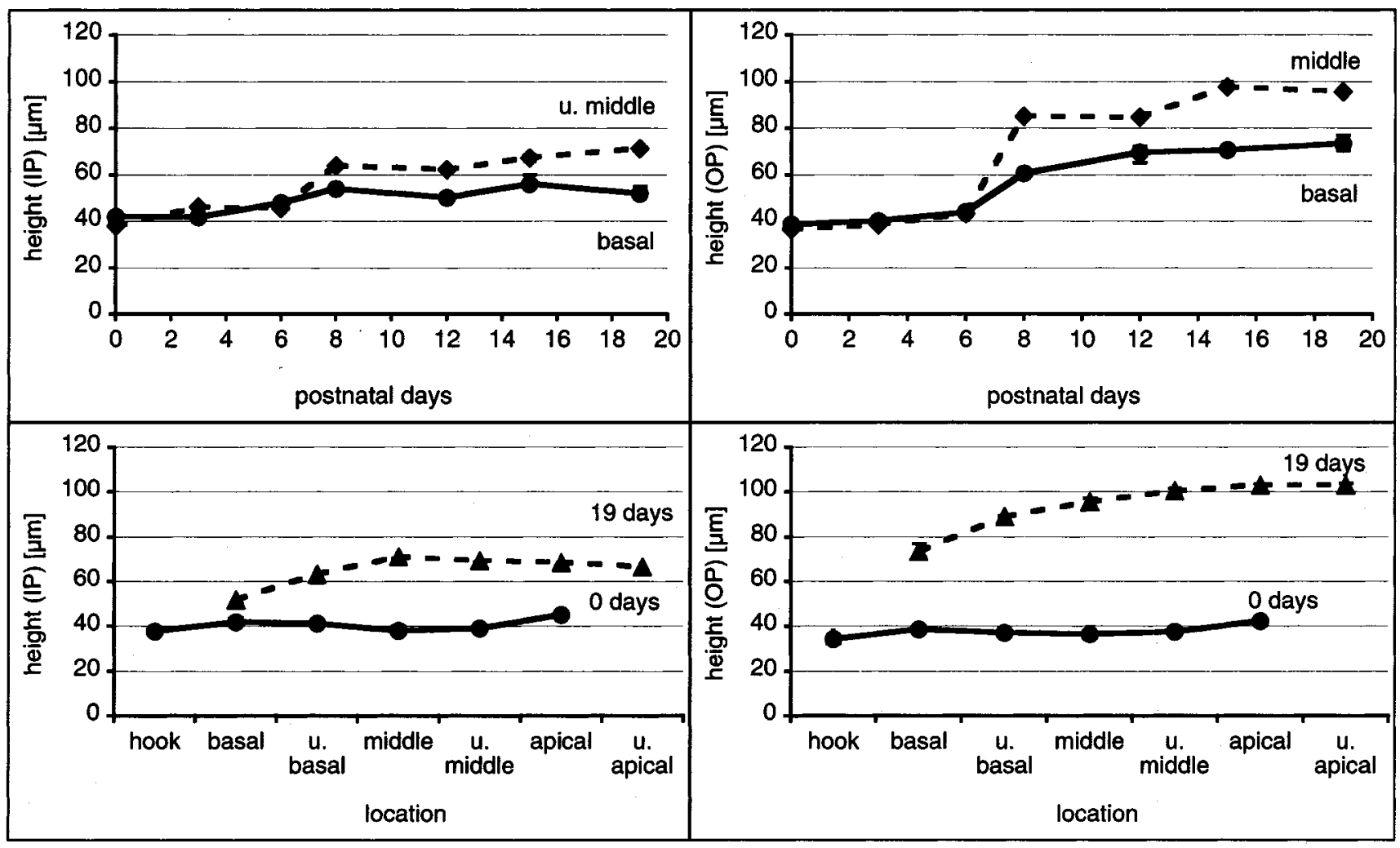

FIG. 13. Growth of the inner and outer pillar cells (IP, OP). Rapid height changes occur between DAB 6 and DAB 8 (upper panels). In adult animals pillar cells are longer in the mid and apical locations of the cochlea (lower panels). The values are the medians and their respective interquartile ranges.

of the same order in the measurements of Souter et al. (1997), less than a factor of 1.3. These numbers are far from the expected fourfold decrease in cochlear dimensions.

\section{Basilar membrane}

The measured width of the basilar membrane in our study was similar to that reported by Plassmann et al. (1987). No significant changes were found after postnatal day 12; this matches the findings of Schweitzer et al. (1996).

Schweitzer et al. (1996) and Souter et al. (1997) reported a decrease in thickness of the basilar membrane between days 12 and 19. In contrast to the latter results, our experiments show a much more complex maturation pattern. Throughout the cochlea, the tympanic cover layer cells decrease in thickness. Furthermore, a translucent noncellular structure, the hyaline mass, develops between the upper fiber band and the lower fiber band of the basilar membrane. The concatenated thickness of the three structures $(T C L, H M$, and $C L$ ) increases between birth and postnatal day 12 . Thereafter, in the basal, upper basal, and middle turn of the cochlea, the total thickness of $T C L, H M$, and $\mathrm{CL}$ decreases to its adult values. At locations further apical, the thickness still increases after postnatal day 12. While in the base of the cochlea some of the reported maturation patterns of cochlear dimensions are similar in previous studies (Schweitzer et al. 1996; Souter et al. 1997), the measured values are quite different, in particular after the HM has developed. In other words, between postnatal days 0 and 6 the concatenated thickness determined for the BM and $\mathrm{CL}$ or the thickness for the BM alone differs less than $10 \%$ between the present and previous studies. After the $\mathrm{HM}$ is formed, however, the differences between previous studies (Plassman et al. 1987; Schweitzer et al. 1996; Souter et al. 1997) and ours approach $100 \%$. The discrepancies are due to differences in the $\mathrm{HM}$, a translucent structure that is subject to severe shrinkage caused by dehydration of the tissue (Edge et al. 1998). Consequently, differences between this and the previous studies can be explained by the different methods used.

Longitudinal gradients are, in general, as reported by Plassmann et al. (1987). In the basal part there is a plateau reaching from the hook region of the cochlea to about $2 \mathrm{~mm}$ from the basal end of the basilar membrane. Thereafter, the thickness of the basilar membrane increases monotonically until it reaches a maximum at about $8.5 \mathrm{~mm}$ from its basal end. In our 


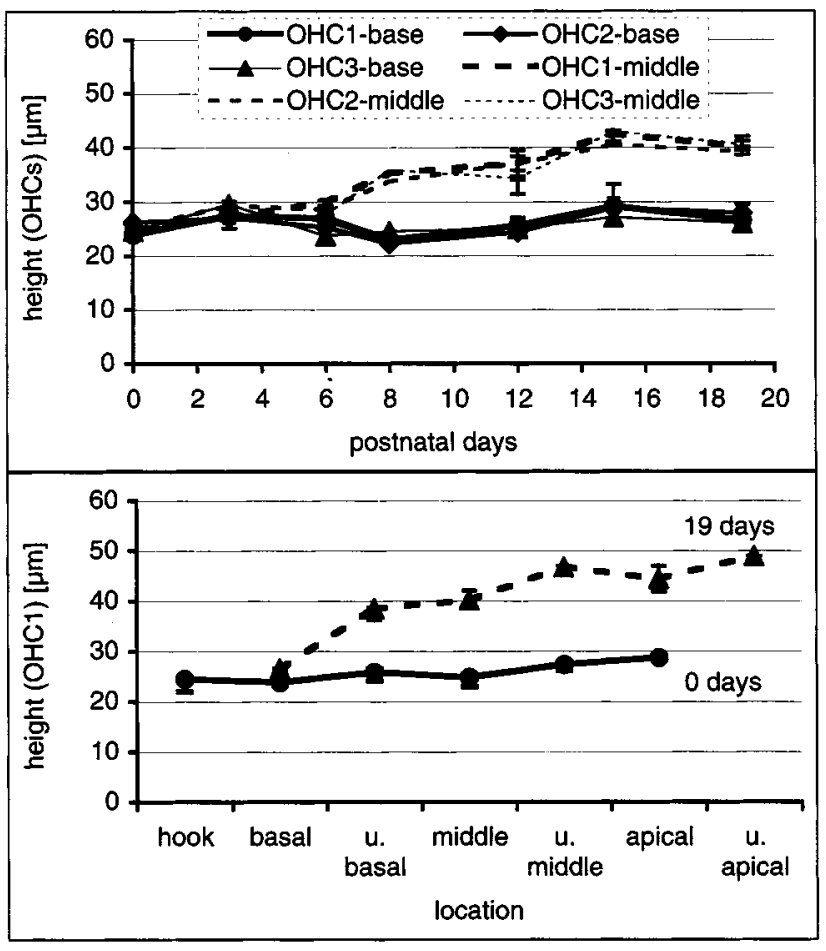

FIG. 14. Growth of the outer hair cells. Rapid height changes occur between postnatal days 6 and 8 (upper panel). This is true for all three rows of outer hair cells. Furthermore, the three rows of outer hair cells were similar in height (upper panel). In adult animals, outer hair cells show longitudinal gradients along the cochlea, but not in immature animals. As demonstrated by the height of first row outer hair cells, the measure increases from base to apex. The changes are small in 0-day-old animals, but clearly observable 19 days after birth. The values are the medians and their respective interquartile ranges.

experiments, the maximum in BM thickness islocated slightly closer to the apex of the cochlea than reported by Plassman et al. (1987). Further towards the apical end of the basilar membrane, the thickness decreases again.

\section{Tectorial membrane}

Almost no information is available about the development of the tectorial membrane in gerbils. Furthermore, whatever data were published for the gerbil tectorial membrane, they have been derived from dehydrated material, which was subjected to severe shrinkage (Souter 1997; Edge et al. 1998). The results of the present experiments show that the tectorial membrane in the basal turn is almost adultlike at postnatal day 12 .

Light microscopic images of the tectorial membrane reveal two distinct segments: a more structured (central) and an amorphous (lateral) part. At postnatal day 6 , the structured part of the tectorial membrane is located mainly above the interdental cells and ends above the pillar heads. It is not clear whether an actual discontinuity exists between the interdental cells and the tectorial membrane at this stage of development. Another, clearly distinct segment of the tectorial membrane extends from the structured part of the tectorial membrane across the outer hair cells. It is unclear whether this structure is tightly attached to H ensen's cells or is free-floating.

During early maturation of the cochlea, the tectorial membrane undergoes shape changes. M ost prominent are those between postnatal days 6 and 12 when the fastest lengthening of Deiters' cells occurs. The growth of these cells pushed the tectorial membrane toward the scala vestibuli. The tectorial membrane appeared as a rigid body that did not retract significantly toward the modiolus. Thus, outer hair cells were finally "pushed below" the tectorial membrane. It is possible that the second distinguishable part of the tectorial membrane, the amorphous extension, remains and forms part of the marginal band. In gerbils it has been shown that the marginal band manifests as a small extension to the body of the tectorial membrane in the base of the cochlea, but manifests as a large, noselike structure in the apex (Edge et al. 1998). The size of the marginal band is adultlike by postnatal day 12 . In other words, during the rapid growth of Deiters' cells and outer hair cells, the marginal band is seemingly developing as well. Because the entire surface area of the tectorial membrane is not changing significantly after postnatal day 6 the marginal band likely develops apart from the structured part of the immature tectorial membrane.

\section{Organ of Corti and its cellular structures}

We find that the cross-sectional area of the organ of Corti increases by a factor of 4 between the day of birth and adulthood. The greatest change occurs between days 6 and 8 and correlates with the growth of Deiters' cells and the lengthening of outer hair cells. Between postnatal day 12 and adult, changes observed in the base of the cochlea are small and insignificant.

Souter et al. (1997) demonstrated that the development of the supporting structures in the inner ear, such as pillar cells, starts in the middle and then spreads toward the base and the apex of the cochlea. This pattern can be confirmed by our experiments. However, in contrast to data of Souter et al. (1997), in our experiments the inner pillar cell did not change its height as much as did the outer pillar cell. The present study revealed a large increase in the height of the outer pillar cell. Furthermore, the rapid growth of both pillar cells occurred at the same time after birth.

In adult animals the stalk of the inner pillar cell, the stalk of the outer pillar cell, and the basilar membrane arcuate zone form a triangle. The angles included in 


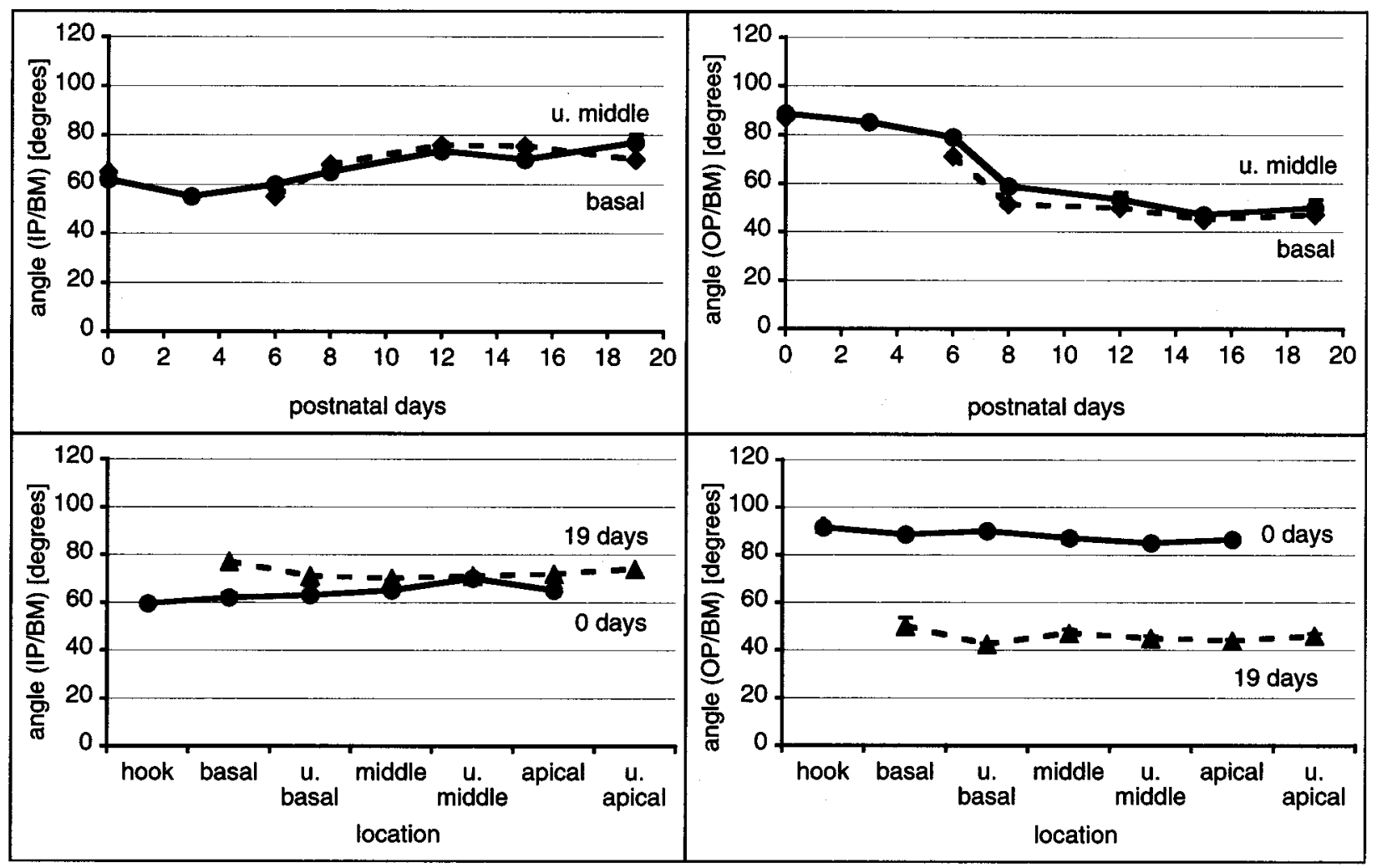

FIG. 15. Angles between the outer pillar stalk and the basilar membrane arcuate zone (OP/BM) and the inner pillar stalk and the basilar membrane arcuate zone (IP/BM). None of the angles measured change along the cochlear partition (lower panels). During development, however, OP/BM decreases and IP/BM slightly increases (upper panels). The values are the medians and their respective interquartile ranges.

this triangle change during development when the pillar cells are growing and the pillar feet separate. As the outer pillar cells grow more than the inner pillar cells, the angle between the outer pillar stalk and the basilar membrane becomessteeper compared with the angle between the inner pillar stalk and the basilar membrane. In particular, the angle between the outer pillar cell (initially about $90^{\circ}$ ) and the basilar membrane decreased to about $50^{\circ}$.

Interestingly, the angles, once achieved in development, do not show differences between more basal and more apical locations in the cochlea. Thus, it is unlikely that these angles provide an additional factor in the frequency-place code along the cochlea. Similarly, the angle between the stalk of the outer pillar cell and the reticular lamina remains constant, not only at different locations in the cochlea but also during the postnatal development of the inner ear. The angles measured in the present study are comparable to those obtained in other studies. For adult animals Souter et al. (1997) measured the angle between the $O P$ and the $B M$ as $50.7^{\circ}$ (47.0 in our study) and the angle between IP and BM as $67^{\circ}$ ( $70.0^{\circ}$ in our study).

In contrast to the above, the angle between a line parallel to the surface of the basilar membrane and a line parallel to the surface of the reticular lamina changes during development. The changes are brought about by the increased height of Deiters' cells and outer hair cells. Furthermore, this angle expands from more basal to more apical locations along the cochlea.

Development from base to apex or vice versa?

Boettcher (1869) and later Retzius (1884) showed that the final development of the inner ear starts in the base of the cochlea and progresses toward the apex. Thisfinding has been confirmed by other investigators (Streeter 1917; Wada 1923; Bast and Anson 1949; Hoyte 1961; Anggard 1965; Pujol and Marty 1970; Tanaka et al. 1979). Contrary to these latter reports, Lorente de No (1933), Larsell et al. (1944a,b), Bredberg (1968), Mair (1973), Romand and Romand (1982), and Souter et al. (1997) showed that the final development of the cochlea starts in the midcochlear location and progresses toward the base and the apex. Our own data show an onset of the period of rapid growth in the upper basal to middle turn of the cochlea. In other words, growth starts about 4.5-6.8 $\mathrm{mm}$ from the base and progresses toward the apex and the base. 


\section{SUMMARY}

With the hemicochlea we have a tool to study cochlear dimensions while avoiding dehydration and embedding protocols that can lead to severe distortion of cochlea preparations. Our experiments show that hydrous structures such as the tectorial membrane and the basilar membrane hyaline matrix are larger compared with measurements in previous studies. As severe distortion of the aforementioned structures has been avoided, the development of the tectorial membrane could be documented. Furthermore, the experiments confirm growth patterns of the cochlea that include a period of remarkably rapid growth between postnatal days 6 and 8 . The growth spurt starts in the middle of the cochlea and progresses toward the base and the apex. Before and after the period of rapid growth, the obser ved gross morphological changes are rather small. It is unlikely that dimensional changes of cochlear structures between postnatal days 12 and 19 contribute significantly in the remapping of the frequency-place code in the base of the cochlea. Instead, changes affecting the stiffness of the cochlear partition might be responsible for the shift in best frequency as observed in CM (H arrisand Dallos 1984), activity of auditory nerve fibers (Echteler et al. 1989; Muller 1996), or in basilar membrane mechanics (O verstreet and Ruggero 1998, 1999).

$O$ uter hair cells that are assumed to be the actuators of the cochlear amplifier are al ready mature at postnatal day 12. Their somatomotile responses are adultlike (He et al. 1994) and their acetylcholine receptors are fully developed (He and Dallos 1999). The cochlear amplifier is apparently functional. H owever, it remains to be answered whether the outer hair cells properly interact with the cochlear partition and, thus, amplify the vibrations of the basilar membrane.

\section{ACKNOWLEDGMENT}

This work was supported by NIH Grant DC00708 and the Deutsche Forschungsgemeinschaft, Ri 699/ 5-2.

\section{REFERENCES}

ANGGARD L. An electrophysiological study of the development of cochlear functions in the rabbit. Acta Otolaryngol. Suppl. 203: 1-64, 1965.

Arjmand E, Harris D, Dallos P. Developmental changes in frequency mapping of the gerbil cochlea: Comparison of two cochlear locations. Hear. Res. 32:93-96, 1988.

BAST TH, ANsO N BJ. The temporal bone and the ear. ThomasSpringfield, IL 1949.

BOETTCHER A U ber Entwicklung und Bau des Gehorlabyrinthsnach Untersuchungen an Saugetieren. Verh. K. Leop. Carol. Dtsch. Akad. Naturforsch. 35:425, 1869.
BoHnE BA. Location of small cochlear lesions by phase contrast microscopy prior to thin sectioning. Laryngoscope. 82:1-16, 1972.

BREDBERg G, Ades HW, EngSTROM H. Scanning electron microscopy of the normal and the pathological altered organ of Corti. Acta Otolaryngol. Suppl. 301:3-8, 1972.

Echteler SM, Arjmand E, Dallos P. Developmental alterations in the frequency map of the mammalian cochlea. Nature. 341:147149, 1989.

ECHTELER SM . Structural correlates of frequency-place map development. Abstr. Assoc. Res. Otolaryngol. 18:442, 1995.

Edge RM, Evans BN, Pearce M, Richter C-P, Hu X, Dallos P Morphology of the unfixed cochlea. Hear. Res. 124:1-16, 1998.

FINK A, SCHNECK CD, HARTMAN AF. Development of cochlear function in the neonate Mongolian gerbil. J. Comp. Psychol. 78:375380, 1972

HARRIS DM, DALLOS P. Ontogenetic changes in frequency mapping in a mammalian ear. Science. 225:741-743, 1984.

HarRis DM, Rotche R, Freedom T. Postnatal growth of cochlear spiral in Mongolian gerbil. Hear. Res. 50:1-6, 1990.

He DZZ, Evans BN, Dallos P. First appearance and development of electromotility in neonatal gerbil outer hair cells. Hear. Res. 78:77-90, 1994.

HE DZZ, DALLOS P. Development of acetylcholine-induced responses in neonatal gerbil outer hair cells. J. Neurophysiol. 81:11621170, 1999.

HOYTE DAN. The postnatal growth of the ear capsule in the rabbit. Am. J. Anat. 103:1-16, 1961.

Ito M, SPICER SS, SCHULTE BA. Cytological changes related to maturation of the organ of Corti and opening of Corti's tunnel. Hear. Res. 88:107-123, 1995.

KRONESTER-FREI A Sodium dependent shrinking properties of the tectorial membrane. Scanning Electr. Microsc. 2:943-948, 1978.

KRONESTER-FREI A. The effect of changes in endolymph ion concentrations on the tectorial membrane. Hear. Res. 1:81-94, 1979.

LaRSELL O, MCCRAdY E, LaRSELL JF. Development of the organ of Corti in relation to the inception of hearing. Arch. Otolaryngol. 40:233-248, 1944a.

LARSELL O, MCCRADY E, LARSELL JF. Development of the organ of Corti in relation to the inception of hearing. Trans. Am. Acad. Ophthamol. Otolaryngol. 48:333-357, 1944b.

LIM DJ. Fine morphology of the tectorial membrane: Its relationship to the organ of Corti. Arch. Otolaryngol. 96:199-215, 1972.

LIM DJ. Fine morphology of the tectorial membrane: Fresh and development. In: M Portmann and J-M Aran eds., INSERM Inner Ear Biology vol 68, pp. 47-60, 1977.

LORENTE DE No R. Anatomy of the eighth nerve. The central projection of the nerve endings of the internal ear. Laryngoscope. 43: $1-38,1933$.

MAIR IWS. Hereditary deafness in the white cat. Acta Otolaryngol. Suppl. 314:5-48, 1973.

MCGUIRT JP, SCHMEIDT RA, SCHULTE BA. Development of cochlear potentials in the neonatal gerbil. Hear. Res. 84:52-60, 1995.

MILLS DM, NorTon SJ, Rubel EW. Development of active and passive mechanics in the mammalian cochlea. Aud. Neurosci. 1:7799, 1994.

MilLs DM, Rubel EW. Development of the cochlear amplifier. J. Am. Soc. Acoust. 100:428-441, 1996

MiLLS DM, RubeL EW. Development of the base of the cochlea: place code shift in the gerbil. Hear. Res. 122:82-96, 1998.

MULLER M, OTt H, BRUNS V. Frequency representation and spiral ganglion cell density in the cochlea of the gerbil Pachyuromys duprasi. Hear. Res. 56:191-196, 1991.

MULLER M. The cochlear place-frequency map of the adult and developing Mongolian gerbil. Hear. Res. 94:148-156, 1996.

NoRTON SJ, BARGONES JY, RubeL EW. Development of otoacoustic emissionsin gerbil: Evidence for micromechanical changesunderlying development of the place code. Hear. Res. 51:73-92, 1991. 
Overstreet EH, Ruggero MA. Basilar membrane mechanics at the hook region of the Mongolian gerbil. Abstr. Assoc. Res. Otolaryngol. 21:721, 1998.

OVERStReEt EH, Ruggero MA. The development of basilar membrane mechanics at the hook region of the Mongolian gerbil cochlea. Abstr. Assoc. Res. Otolaryngol. 22:537, 1999.

Plassmann W, Peetz W, Schmidt M. The cochlea in gerbilline rodents. Brain Behav. Evol. 30:82-101, 1987.

PUJOL R, MARTY R. Postnatal maturation in the cochlea of the cat. J. Comp. Neurol."139:115-126, 1970.

RETZIUS G Das Gehororgan der Wirbeltiere Bd. II. Das Gehororgan der Reptilien, der Vogel und der Saugetiere Samson and Wallin Stockholm 1884.

RichteR C-P, DALLos P. Micromechanics contribute to the shift in the frequency place code in developing gerbils. Abstr. Assoc. Res. Otolaryngol. 23:870, 2000.

ROMAND R, ROMAND MR. Myelination kinetics of spiral ganglion cells in the kitten. J. Comp. Neurol. 204:1-5, 1982.

RubeL EW, RyALs BM. Development of the place principle: acoustic trauma. Science. 219:512-514, 1983.

RUBSAMEN R, LIPPE WR. The development of cochlear function. RubeL EW, PopPeR N, FAY RR. Development of the auditory system Spinger-Verlag New York 1997, 193-270.

SCH WeitZer L, LUTZ C, H obbs M, WeaVer SP. Anatomical correlate of the passive properties underlying the developmental shift in the frequency place map of the mammalian cochlea. Hear. Res. 97:84-94, 1996.

Souter M, NeViLl G, Forge A. Postnatal development of membrane specifications of gerbil outer hair cells. H ear. Res. 91:43-62, 1995.

Souter M, Nevill G, Forge A. Postnatal maturation of the organ of Corti in gerbils: Morphology and physiological responses. J. Comp. Neurol. 386:635-651, 1997.

Streeter GL. The development of the scala tympani, scala vestibuli and perioticular cistern in the human embryo. Am. J. Anat. 21:299-320, 1917.

TANAKa Y, SAKaY N, TeRAYAma Y. Organ of Corti in the human fetus: Scanning and transmission electronmicroscopic studies. Ann. Otol. Rhinol. Laryngol. 88:749-758, 1979.

WADA T. Anatomical and physiological studies on the growth of the inner ear of the albino rat. Am. Anat. Mem. 10:1-174, 1923.

WOOLF NK, RYAN AF. The development of auditory function in the cochlea of the Mongolian gerbil. Hear. Res. 13:277-283, 1984.

WOOLF NK, RYAN AF, H ARRIS JP. Development of mammalian endocochlear potential: normal ontogeny and effects of anoxia. Am. J. Physiol. 250:R493-R498, 1986.

WOOLF NK, RYAN AF. Contributions of the middle ear to the development of function in the cochlea. Hear. Res. 35:131-142, 1988.

YANCEY C, DALLOS P. Ontogenetic changes in cochlear characteristic frequency at a basal turn location as reflected in the summating potential. Hear. Res. 18:189-195, 1985. 